\title{
Implementasi E-Commerce Untuk Jual Beli Sparepart Sepeda Motor Di Toko Expo Motor
}

\author{
Fauriatun Helmiah ${ }^{1}$, Dewi Maharani ${ }^{2}$, Nurwati ${ }^{3}$ \\ Program Studi Manajamen Informatika STMIK ROYAL KISARAN \\ Jl. Prof. H.M. Yamin No 173 Telp. 0623-41079, Fax. 0623-42366 \\ Email: fahel_mi2@yahoo.com,dewimaharani15@gmail.com,nurwati763@gmail.com
}

\begin{abstract}
Expo Motor Shop is a company engaged in the sale of motorcycle spare parts. Conventional and manual promotion and data collection systems slow down market share outreach achieved by the Expo Motor Store. Therefore, marketing and sales through the Internet or E-Commerce are made which aim to provide convenience to sellers and buyers in the process of buying and selling products and customers. Visual modeling uses the Unified Modeling Language (UML). And in the end e-commerce buying and selling can bring benefits to the company in marketing and meeting customer needs for up-to-date information.
\end{abstract}

Keywords: E-Commerce, Expo Motor Shop, UML

Abstrak-Toko Expo Motor adalah sebuah perusahaan yang bergerak dibidang penjualan sparepart sepeda motor. Sistem promosi dan pendataan yang konvensional dan manual membuat lambatnya penjangkauan pangsa pasar yang diraih oleh Toko Expo Motor. Oleh sebab itu dibuatlah suatu pemasaran dan penjualan melalui internet atau E-Commerce yang bertujuan untuk memberikan kemudahan kepada penjual dan pembeli dalam melakukan proses jual beli dan pendataan produk dan pelanggan. Pemodelan visual menggunakan Unified Modeling Language (UML). Dan pada akhirnya e-commerce jual beli ini dapat membawa keuntungan bagi perusahaan dalam memasarkan dan memenuhi kebutuhan pelanggan akan informasi yang up to date.

Kata kunci: E-Commerce, Toko Expo Motor, UML.

\section{PENDAHULUAN}

Internet merupakan salah satu jaringan global yang menghubungkan jaringan komputer diseluruh dunia, sehingga memungkinkan terjalinnya komunikasi dan interaksi antar satu perusahaan dengan konsumen. dalam hal ini, banyak di temukan konsumen melakukan transaksi jual beli dengan cara konsumen harus datang sendiri ke lokasi dan pembayaran dilakukan secara tunai. E-commerce atau biasa disebut Perdagangan elektronik atau e-dagang adalah pembelian, penjualan, pemasaran barang dan jasa melalui internet atau jaringan komputer. Seluruh komponen yang ada dalam perdagangan diaplikasikan kedalam E-commerce seperti Customer Service, layanan produk, cara pembayaran dan cara promosi. Customer juga terkadang kesulitan dalam sistem pembayaran yang dilakukan apabila berada di luar kota. Konsumen juga dapat melakukan pengecekan barang baru yang sudah ter-update. Salah satu solusi untuk mengatasi masalah di atas yaitu dibuat aplikasi E-commerce penjualan dan pemesanan berbasis web yang diharapkan dapat membantu mengatasi hambatan-hambatan yang dimiliki oleh Toko Expo Motor. Tujuan dari penelitian ini adalah Dengan adanya aplikasi sistem informasi e-commerce dapat mengetahui secara terperinci 
penjualan dan pemesanan serta data pembelian barang agar minim dari kesalahan dan mempermudah pekerjaan dan diharapkan dapat membantu calon pembeli dalam membeli dan memesan sparepart Sepeda Motor di Toko Expo Motor.

\section{METODOLOGI PENELITIAN}

Kerangka kerja ini merupakan langkah-langkah yang akan dilakukan dalam rangka penyelesaian masalah yang akan dibahas sehingga sasaran akhir dari penelitian dapat dicapai. Pengumpulan Data, Mengolah Data, Merancang Aplikasi E-Commerce, Mengimplementasikan Sistem, Menguji Sistem.

\section{HASIL DAN PEMBAHASAN}

\subsection{Analisa Prosedur}

Analisis prosedur yang berjalan menjelaskan sistem yang saat ini ada pada Toko Expo Motor terdiri dari :

a. Proses permintaan barang masih dilakukan dengan membuat PO (Purchase Order). Kemudian dikirim ke supplier.

b. Ketika barang masuk ke dalam inventory, dilakukan pengecekan dengan perhitungan fisik kemudian data di input ke dalam Buku Besar.

c. Ketika barang keluar petugas menghapus data barang dengan cara manual.

d. Pembuatan laporan persediaan akhir dengan MS.Excel dan dilakukan pengecekan dari nota transaksi.

\subsection{Tampilan Antar Muka}

Berikut ini tampilan sistem yang dirancang pada e-commerce:

a. Halaman Login Administrator

2 Login Aoministrator

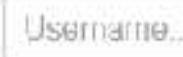

Password.

\section{$\log \ln$}

C. 2017

Gambar 1. Tampilan Halaman Login Administrator 
b. Halaman Menu Utama

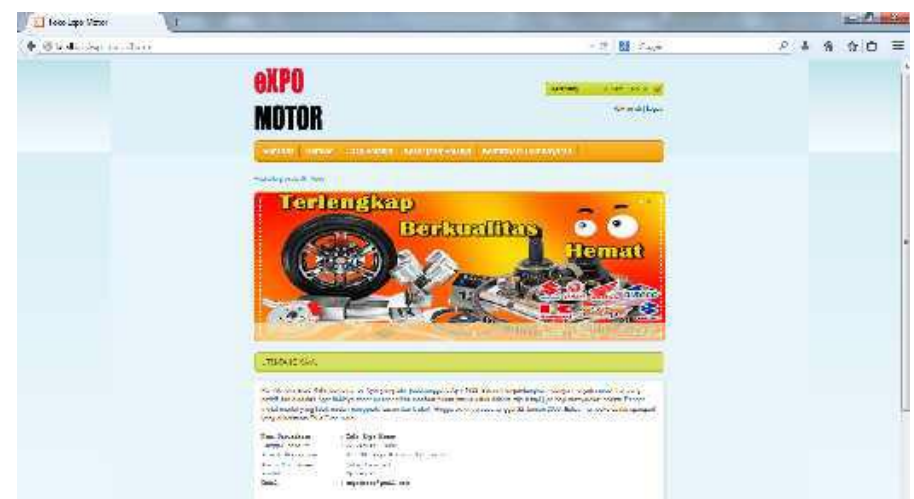

Gambar 2. Tampilan Halaman Menu Utama

c. Halaman Daftar Member Baru

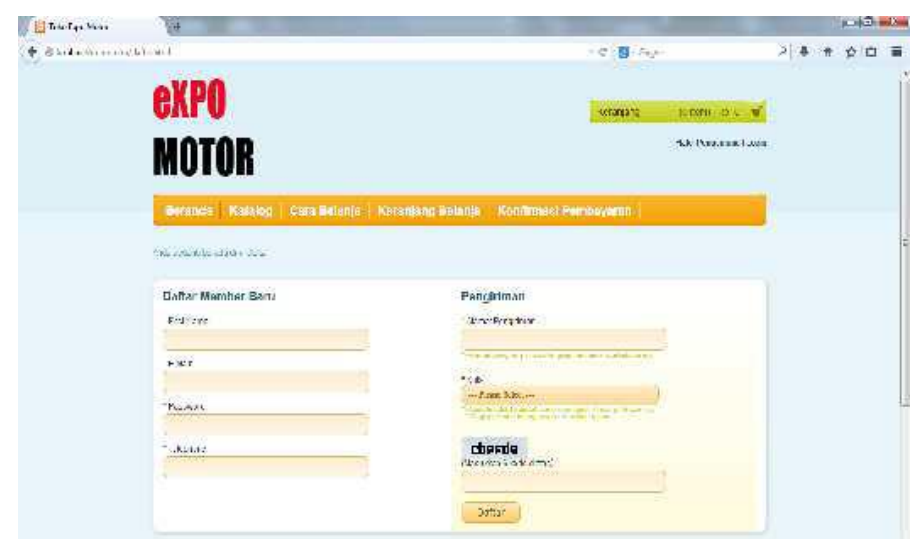

Gambar 3. Tampilan Halaman Daftar Member Baru

d. Halaman Login User

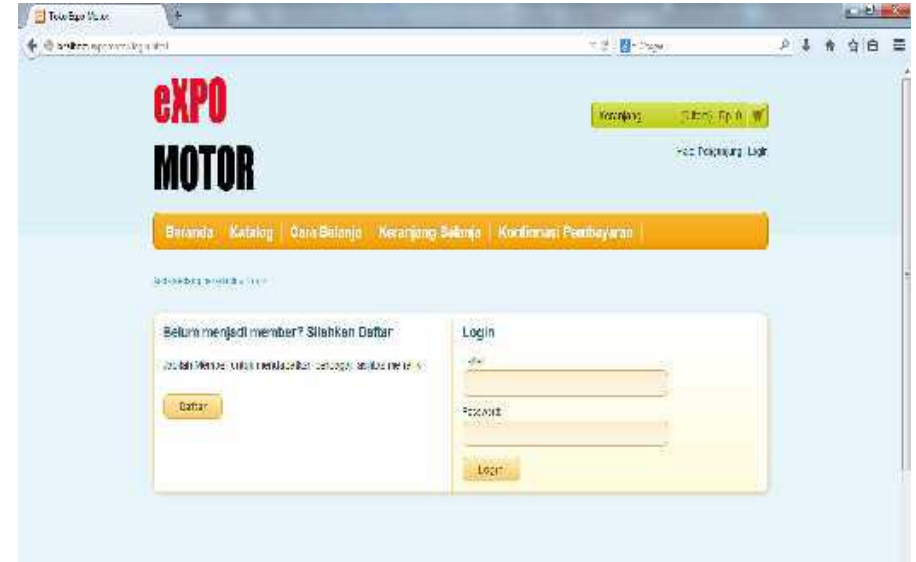

Gambar 4. Tampilan Halaman Login User 
e. Halaman Katalog

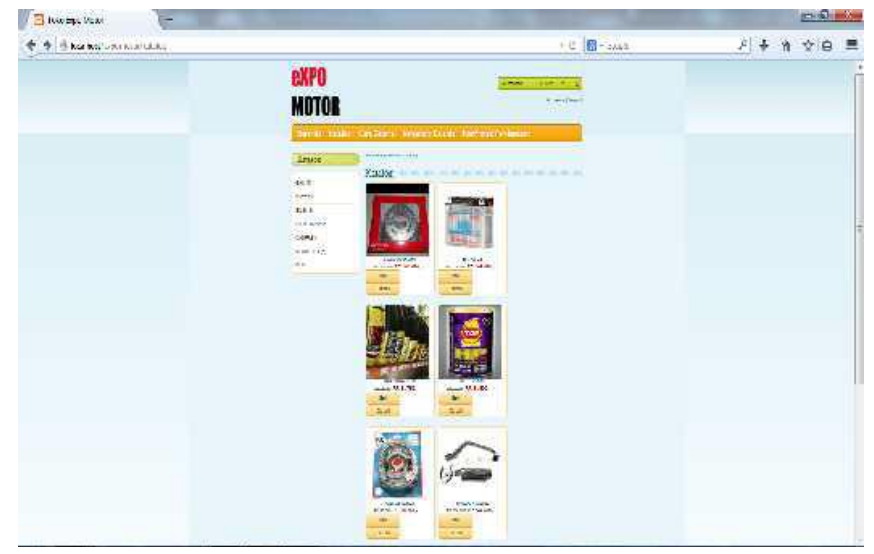

Gambar 5. Tampilan Halaman Katalog

f. Halaman Cara Belanja

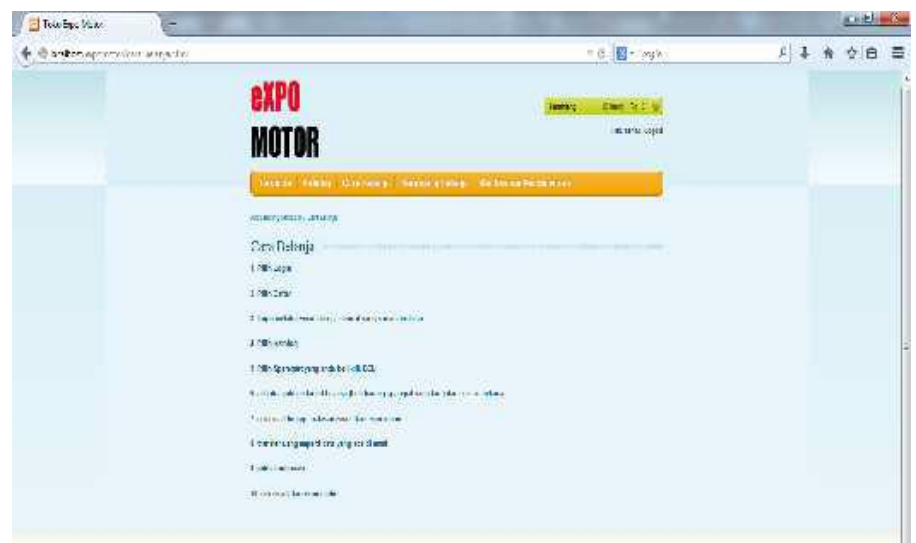

Gambar 6. Tampilan Halaman Cara Belanja

g. Halaman Keranjang Belanja

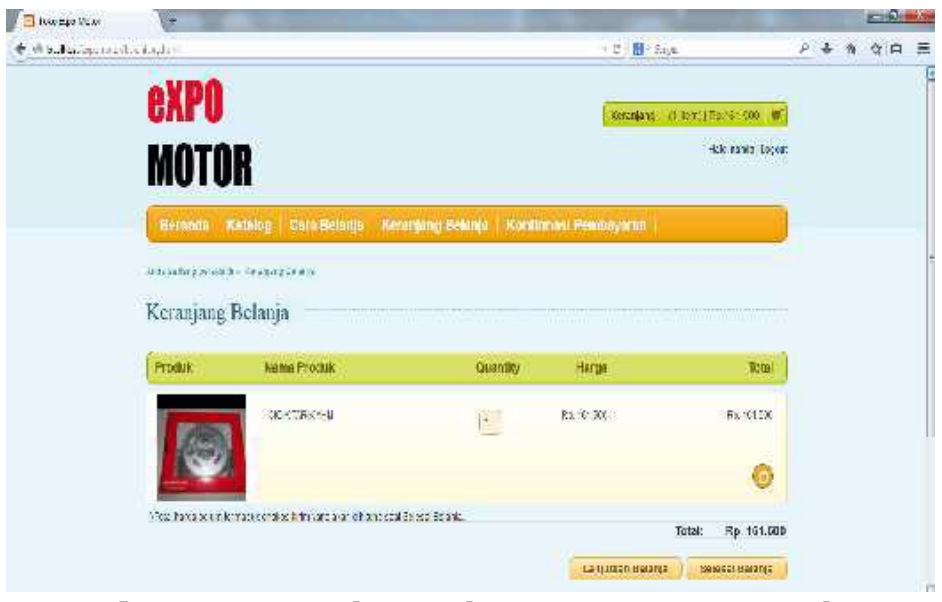

Gambar 7. Tampilan Halaman Keranjang Belanja 
Prosiding Seminar Nasional Riset Information

Science (SENARIS)

h. Halaman Data Pemesanan

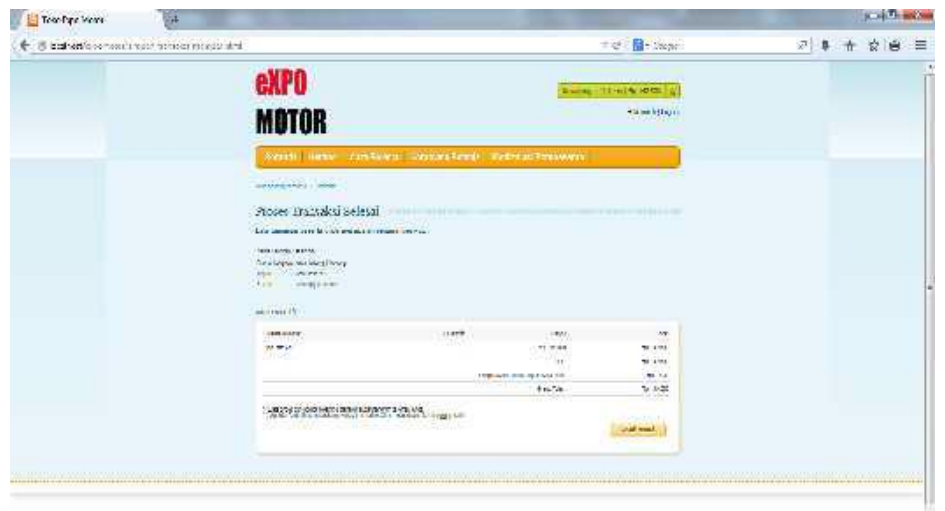

Gambar 8. Tampilan Halaman Data Pemesanan

i. Halaman Laporan Penjualan Harian

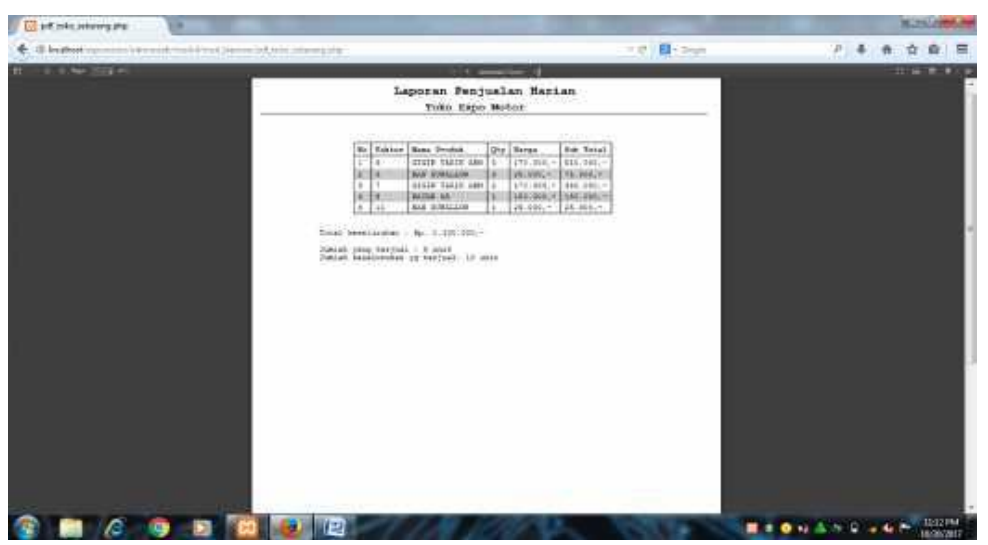

Gambar 9. Desain Halaman Laporan Penjualan Harian

j. Halaman Laporan Penjualan Bulanan

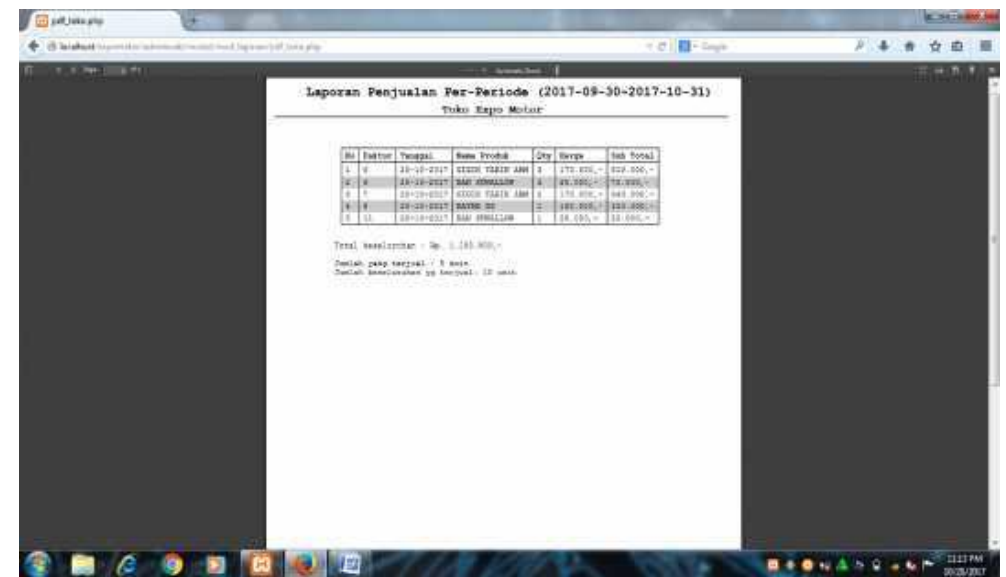

Gambar 10. Desain Halaman Laporan Penjualan Bulanan

Implementasi E-Commerce Untuk Jual Beli Sparepart Sepeda Motor (Fauriatun Helmiah) | 1095
ISSN: 2686-0260

September 2019

Hal:1091-1097 


\subsection{Hasil}

Berdasarkan proses pengujian yang telah dilakukan sebelumnya, maka dapat ditarik sebuah hasil dari pengujian sistem tersebut. Hasil pengujian ini memaparkan kesesuaian sistem yang dibuat terhadap apa yang diharapkan user. Berikut ini adalah hasil pengujian terhadap sistem yang telah dirancang:

Tabel 1. Hasil Pengujian Sistem

\begin{tabular}{|c|c|c|c|}
\hline Nama Tes & Skenario Uji & Hasil Yang Di Harapkan & Hasil \\
\hline \multirow[t]{2}{*}{ Login } & $\begin{array}{l}\text { Input Login (Jika } \\
\text { Benar) }\end{array}$ & Tampil menu utama & Berhasil \\
\hline & $\begin{array}{l}\text { Input Login (Jika } \\
\text { Salah) }\end{array}$ & $\begin{array}{l}\text { Tetap di halaman login dan menampilkan } \\
\text { pesan kesalahan kode user dan password }\end{array}$ & Berhasil \\
\hline $\begin{array}{l}\text { Member } \\
\text { Baru }\end{array}$ & $\begin{array}{l}\text { Tambah, simpan, } \\
\text { hapus, } \\
\text { Edit }\end{array}$ & $\begin{array}{l}\text { Data dapat dimasukkan ke dalam } \\
\text { database, dihapus, diedit dan ditambah }\end{array}$ & Berhasil \\
\hline Berita & $\begin{array}{l}\text { Tambah, } \\
\text { simpan, hapus, } \\
\text { edit }\end{array}$ & $\begin{array}{l}\text { Data dapat dimasukkan ke dalam } \\
\text { database, dihapus, diedit dan ditambah }\end{array}$ & Berhasil \\
\hline $\begin{array}{l}\text { Kategori } \\
\text { Sparepart }\end{array}$ & $\begin{array}{l}\text { Tambah, } \\
\text { simpan, hapus, } \\
\text { edit }\end{array}$ & $\begin{array}{l}\text { Data dapat dimasukkan ke dalam } \\
\text { database, dihapus, diedit dan ditambah }\end{array}$ & Berhasil \\
\hline Promo & $\begin{array}{l}\text { Tambah, simpan, } \\
\text { hapus, } \\
\text { Edit }\end{array}$ & $\begin{array}{l}\text { Data dapat dimasukkan ke dalam } \\
\text { database, dihapus, diedit dan ditambah }\end{array}$ & Berhasil \\
\hline List Barang & $\begin{array}{l}\text { Tambah, } \\
\text { simpan, hapus, } \\
\text { edit }\end{array}$ & $\begin{array}{l}\text { Data dapat dimasukkan ke dalam } \\
\text { database, dihapus, diedit dan ditambah }\end{array}$ & Berhasil \\
\hline $\begin{array}{l}\text { List } \\
\text { Konfirmasi }\end{array}$ & $\begin{array}{l}\text { Tambah, } \\
\text { simpan, hapus, } \\
\text { edit }\end{array}$ & $\begin{array}{l}\text { Data dapat dimasukkan ke dalam } \\
\text { database, dihapus, diedit dan ditambah }\end{array}$ & Berhasil \\
\hline Laporan & $\begin{array}{l}\text { Pilih Jenis } \\
\text { Laporan }\end{array}$ & Tampil laporan yang dipilih & Berhasil \\
\hline Keluar & Close & Keluar dari sistem aplikasi & Berhasil \\
\hline
\end{tabular}

\section{KESIMPULAN}

Berdasarkan penulisan ini, telah diuraikan dengan jelas bagaimana proses jual beli yang telah berjalan dan sistem yang baru pada Toko Expo Motor, sehingga dapat diambil beberapa kesimpulan:

a. Merancang sebuah sistem E-Commerce menjadi suatu media penjualan sparepart sepeda motor.

b. Direkomendasikan untuk digunakan di Toko Expo Motor untuk mendukung bisnis perusahaan dari transaksi yang sebelumnya bersifat manual mengarah kepada penjualan, pembelian, up date stock barang dan transaksi untuk kemudahan atau kelancaran dan bertransaksi.

c. Untuk mempermudah melakukan tahap implementasi E-Commerce.

d. Dengan menggunakan UML sebagai media visualisasi dari perancangan sistem dapat membuat model yang dirancang semangkin mendekati realitas. Sehingga mempermudah para pengembang dalam melakukan pengembangan sistem. 


\section{DAFTAR PUSTAKA}

[1] Arcanggih, Diaz Junay dkk. IMPLEMENTASI E-COMMERCE SEBAGAI MEDIA PROMOSI DAN PENJUALAN SECARA ELEKTRONIK. Jurnal Administrasi Bisnis (JAB). Malang : Vol 14 No 1 September 2014

[2] Hendriansyah. IMPLEMENTASI DATA FLOW DIAGRAM PADA PERANCANGAN WEBSITE ECOMMERCE. Jurnal IPTEK. Palembang: juli 2014

[3] Hermawan, Indra dan Kurnia, Ade Dian. Sistem Informasi Pemesanan Paket Pengantin Berbasis WEB Pada Yuni Salon Duku Puntang Kabupaten Cirebon. Jurnal Online ICT STMIK IKMI. Majasam Cirebon : Vol.12 No.2 Desember 2014

[4] Kauffman, J Robert. Electronic Commerce Research and Aplications. Journal homepage Singapore : Available online 20 January 2012

[5] Maulana, Miftah Shabur dkk. IMPLEMENTASI E-COMMERCE SEBAGAI MEDIA PENJUALAN ONLINE. Jurnal Administrasi Bisnis (JAB). Malang : Vol. 29 No. 1 Desember 2015

[6] Nilasari, Senja. 2014. Jago Membuat Website Geratis \& Cepat. Cipayung - Jakarta timur: Dunia komputer.

[7] Rejeki, Artati Sri Rara dkk. Perancangan dan Pengaplikasian Sistem Penjualan Pada "Distro Smith" Berbasis E-Commerce. Jurnal Teknologi Informasi DINAMIK Volume 16, No 1, juli 2011 : $150-159$.

[8] http://www.noficahyono.com/2015/07/perancangan-sistem-informasi_13.html. diakses tanggal 20 Mei 2017

[9] http://indonesia.smetoolkit.org/id/content/435/penggolongan-bahan-anda. diakses tanggal 21 Mei 2017

[10] https://catursaja.wordpress.com/2015/30/4/ diakses pada tanggal 22 Mei 2017 